\title{
The interaction of drill and practice and error training with individual differences
}

\author{
Annette Kluge $\cdot$ Sandrina Ritzmann • \\ Dina Burkolter · Jürgen Sauer
}

\begin{abstract}
This article examines the question of whether the effectiveness of training methods in vocational training settings is modified by trainee characteristics. General mental abilities, cognitive style and conscientiousness were measured as person variables that were expected to influence the effectiveness of training methods. Being trained on a simulated process control environment as an example for a complex technological task for $5 \mathrm{~h}, N=38$ participants received either drill \& practice (D\&P) or error training (ET) as two distinct training methods. A 70-minute transfer test followed 9 weeks later, in which the trainees had to manage familiar (near transfer) as well as unfamiliar fault states (far transfer). The results showed that highability trainees benefited more from D\&P than from ET, whereas low-ability trainees benefited equally well from either training method. Furthermore, participants with a highly flexible cognitive style benefited more from D\&P rather than ET. Also participants low in conscientiousness profited more from D\&P. The findings are indicative of the tentative benefits of using learner-tailored training methods, suggesting that this person-centered approach is worthy of further exploration.
\end{abstract}

A. Kluge $(\bowtie) \cdot$ D. Burkolter

Business and Organizational Psychology,

University of Duisburg-Essen, Lotharstr. 65,

47057 Duisburg, Germany

e-mail: annette.kluge@uni-due.de

\section{S. Ritzmann}

Research Institute for Organizational Psychology,

University of St. Gallen, Varnbüelstrasse 19,

9000 St. Gallen, Switzerland

\section{J. Sauer}

Department of Psychology, University of Fribourg,

Rue de Faucigny 2, 1700 Fribourg, Switzerland
Keywords Training - Vocational education and training Drill \& practice $\cdot$ Error training · Individual differences . Process control

\section{Introduction}

Vocational education and training is a topic of growing importance for whole economies, but also for companies and the single trainee or employee. The European Union (EU), for example, stresses that the ability to continue to learn will be crucial in the world's globalized economy and its increasingly diverse societies (European Commission 2008a), with effects on competitiveness and economic prosperity, but also on employability or personal fulfillment of people (European Commission 2008b). While on a societal level, a major focus is the educational system installed to train the future workforce (e.g., Bosch and Charest 2008; Hanhart and Bossio 1998), the European Commission also calls for a focus on the individual learner with personalized approaches to learning. The EU argues that teaching which is better tailored to the particular needs of each learner can increase interest and improve the attitude toward learning activities and therefore improve the results of trainees (European Commission 2008b). The underlying assumption is that there is no one-fits-all training and teaching approach. But which approach fits whom? This article will concentrate on the question of how training methods interact with individual characteristics and learning styles. Research in the area of learning styles actually shows that trainees feel differently attracted by varying modes of learning. Some trainees prefer to learn with a clear structure and instruction, while others prefer to explore a problem space by themselves in order to build a mental representation on their own (Cassidy 2004; de Jong 
et al. 2006). Most of the latter research has been conducted in higher education settings and has focused on academic, text-based learning. However, less research is available concerning workplace learning or vocational training (de Jong et al. 2006), and especially the interaction of individual characteristics with training methods has rarely been studied.

In this study, we have investigated the interaction effects of training methods with individual differences in the area of process control as an example of a highly technologydependent complex task, as found in different industrial sectors. Our approach is innovative in two ways: To date, the focus of research in process control mainly concentrated on individual characteristics of operators in terms of subjective states or traits on the one hand (Burkolter et al. 2009), or the quality of training on the other (e.g., Patrick et al. 1999), but their interaction has hardly ever been explored further (except e.g., Gully et al. 2002). Second, new training approaches have recently become fashionable in vocational training, partly as a result of governmental initiatives and are widely replacing traditional training methods in many companies (German Federal Institute for Vocational Education and Training 2008; Watkins and Marsick 1992). We take these new approaches into account and take a closer look at their interaction with trainee characteristics.

\subsection{The current trend: "Your last mistake is your best teacher!"}

Since in the early 1990s, the "constructivist revolution" (Mayer 2004) has brought new conceptions of learning and the demand for life-long learning is omnipresent, it has become common practice in large organizations to arrange training and personnel development in terms of learnercentered, self-directed discovery learning. Life-long learning and embedded continuous learning strategies such as desk top learning or learning laboratories offering selflearning material and online learning resources are suggested design principles to also connect individual learning with organizational learning (Watkins and Marsick 1992). Fostering self-directed learning is also supposed to be of great value because it is assumed that the acquired skills can also be more easily transferred to different occupational and workplace situations and are not strictly attached to problems for which the skills were originally acquired. So therefore the new conceptions of learning are also said to support near and far transfer. Near transfer means to transfer learned skills and acquired knowledge to similar questions and problems to those they have practiced in a training situation. Far transfer, also called adaptive transfer, means to transfer acquired skills and knowledge to problems which can also occur at the workplace, but which have not been practiced and trained before (Leberman et al. 2006).

To prepare the future personnel for continuous learning and near and far transfer, most organizations and production sites changed their vocational training strategies from a supervisor-centered approach to a learner-centered workplace-oriented and discovery-learning approach, in which much emphasis is put on active and experiential learning as a practical mode of learning (Postle 1993). These constructivist training arrangements often have an open character and place a great emphasis on learner activities (de Jong 2006). Using simulations and semantically rich training material, workplace-oriented learning draws strongly on learning from mistakes. An often cited statement is: "Your last mistake is your best teacher!".

By using error training (ET) in vocational training, two different underlying theoretical approaches are interwoven: constructivist learning theories and action theory. From a constructivist's point of view, "learning is an active process in which learners are active sense makers who seek to build coherent and organized knowledge" (Mayer 2004, p. 14). Because students should actively construct knowledge themselves, the constructivist approaches are basically discovery oriented. Learners are supposed to discover and construct essential information in a minimally guided environment, also named discovery learning, problembased learning or inquiry learning (Kirschner et al. 2006). Using minimal guidance is supposed to challenge students to solve authentic problems in information-rich settings based on the assumption that developing solutions leads to valuable learning experiences.

But research evidence mainly from school settings summarized by Kirschner et al. (2006) and Mayer (2004) shows that unguided or minimal instruction is not as effective as a guided approach to learning. Instead, Kirschner et al. (2006) criticize that minimally guided instruction is likely to be ineffective because it is not considering the characteristics of working memory and long-term memory as fundamental structures that constitute the human cognitive architecture. The latter is taken account of in cognitive load theory (Sweller 1988, 2006). The minimally instructed learning in a highly complex environment may generate a heavy working memory load which impedes the learning process more than it supports it (Kirschner et al. 2006). Mayer (2004) refers to this as the constructivist teaching fallacy "because it equates active learning with active teaching" (p. 15).

The action theory foundation of ET proposed by Frese and Zapf (1994) assumes action-oriented mental models as the basis of work-related actions (Keith and Frese 2008). As a cognitive structure, the learner's action-oriented mental model, e.g., of a technical system or machine, entails assumptions about how the system works based on a 
first theoretical overview of its functionality, which enables the learner to operate the system during normal operations. The more adequate the mental model, the more successful learners' actions turn out to be. When a learner experiences an error, this error serves as important feedback, indicating that the learner's mental model is not adequate and needs correction. Keith and Frese (2008) view their approach of looking at errors as informative feedback as consistent with other theories that stress the importance of feedback for learning (Kluger and DeNisi 1996; Latham and Locke 1991).

The psychologically relevant mechanisms of ET are experiencing errors, seeing the consequences of such errors and receiving feedback which requires and stimulates effortful analytic learning processes and deeper, more thoughtful processing. Taking a vocational learning perspective in particular, Keith and Frese (2008) argue that because the transfer context for vocational learning is open, disruptive and ambiguous, transfer situations strongly imply the chance to make errors (Heimbeck et al. 2003). It is argued that by also providing the use of errors in the training context, the distance between transfer situation and training situation is reduced. Thus, ET should facilitate transfer of performance (Heimbeck et al. 2003, p. 337). According to Keith and Frese (2008), error training is characterized by two aspects that distinguish it from proceduralized training and purely exploratory training: (1) learners are given minimal guidance and are encouraged to actively explore and experiment on their own. They are asked to work independently by using the provided manuals on difficult technical learning tasks, which inevitably leads to many errors; and (2) learners are told to expect these errors to occur when they begin their training task and are explicitly encouraged to make errors. Additionally, the positive informative feedback on errors for learning is emphasized (Frese et al. 1991). Neither in proceduralized training nor in exploratory training does the positive framing of errors occur.

Research evidence comes mainly from studies in vocational and occupational contexts such as the training of software skills (Frese et al. 1991), decision making in Air Traffic Control (Gully et al. 2002) or driver training (Ivancic and Hesketh 2000). From this vocational training perspective, different strategies for using errors in trainings have been developed and evaluated, e.g., by Lorenzet et al. (2005) or Dormann and Frese (1994). Guided error training in combination with supported correction proved to be superior for skill development (Lorenzet et al. 2005): Guiding trainees into and out of errors leads to better performance and increased self-efficacy on their part than avoiding errors during training. But rather than a practice of just letting trainees make errors, additional instruction in managing the emotional processes of experiencing errors is needed as a basis to foster short- and medium-term transfer (Heimbeck et al. 2003). The overall effectiveness of errormanagement training was confirmed by a meta-analysis which found a medium effect size $(d=.44$; Keith and Frese 2008). The effect size increased when one of the following moderators was present: (a) communication of clear and unequivocal feedback, (b) measurement of test performance rather than of training performance or (c) existence of adaptive transfer (Ivancic and Hesketh 2000). As summarized by Kluge et al. (2009), the success of ET depends very much on the amount and quality of guidance and assistance given to the learners.

In summary, the current trend of using mistakes for promoting the learning process is strongly questioned by instructional psychologists because of its ignorance of the human cognitive architecture and strongly supported by organizational psychologists because of its benefits for adaptive transfer of vocational skills.

\subsection{Traditional approaches: "Practice makes perfect"}

Before the "constructivist revolution", traditional training methods and learning in vocational contexts were much more oriented toward the approach of a supervisor working closely together with, and strongly guiding and advising, an apprentice. Observational learning and modeling were the preferred teaching methods (Hacker and Skell 1993; Sonntag 1989). This meant, first, observing a supervisor who demonstrates and explains the main steps of a skill to be learned; second, repeating what has been observed under the guidance of the supervisor who corrects in case of mistakes, and third, practicing the skill until a certain level has been reached, accompanied by performancerelated feedback. In these traditional training methods, it is generally assumed that "practice makes perfect!".

In our understanding, "traditional" or "strongly structured" training situations have a strong instructional specification and include guidelines on how to proceed to learn and acquire a predefined schema or rule. This is enhanced by repetitive work on a task based on a given schema or checklist as, for example, used in "Drill \& Practice" (D\&P, e.g., Ericsson et al. 1993).

As outlined in the review by Kluge et al. (2009), the psychologically relevant mechanisms of practice is proceduralization of skills (Anderson et al. 1997). Merrill (2001) emphasizes that active practice is the single most neglected aspect of instruction, although results reported by Colquitt et al. (2000) strongly support the principle holding that acquired procedural skills are the best predictor for transfer performance. A common training method that directly incorporates rehearsal, repetition and periods of practice is D\&P (Hagman and Rose 1983; Schendel and Hagman 1982; Ginzburg and Dar-El 2000) which was 
mainly investigated in non-dynamic task, or "deliberate practice", which is used in e.g., sports and has empirically showed to be effective (Ericsson et al. 1993). Summarized by Kluge et al. (2009), research evidence from vocational settings provided by Foss et al. (1989), Kontogiannis and Shepherd (1999), Mattoon (1994), and Morris and Rouse (1985) shows that practice improves performance best. Based on the cognitive load theory briefly introduced above, practice in terms of "worked examples" and "parttask practice" is strongly proposed e.g., by van Gog et al. (2008) or van Merrienboer et al. (2003) to effectively support schema construction and automation in the initial, novice phase of skill acquisition (van Gog et al. 2005).

In summary, the traditional approach demonstrates the advantage of proceduralization for tasks that incorporate fixed sequences. But not much is known about the potential of D\&P to support the transfer of skill to novel situations.

\subsection{The present study}

Although, depending on the training objectives, both training approaches seem generally reasonable and useful, many organizations increasingly rely on the expectation that error training will show positive effects on the transfer of skills to novel situations to be solved (Keith and Frese 2008) and, therefore, far transfer. But organizations have also been confronted with the fact that learners can have difficulties, get frustrated and that training objectives are only reached by certain target groups (Kluge 2007), such as university students versus apprentices, who have favorable preconditions for these training formats.

Although there is some knowledge available about individual differences, such as intelligence, personality and learning styles that are addressed in the context of schools and university learning (e.g., Jonassen and Grabowski 1993), little is known about individual differences in the context of workplace-oriented and vocational training. As we reviewed and evaluated several training methods for their usefulness for learning complex tasks (Kluge et al. 2009), we found that the preconditions relevant for acquiring knowledge, skills and abilities of the single learner were widely ignored.

In this paper, we raise the issue of considering the interaction between individual differences and training methods for process control tasks. Process control is a complex and cognitively demanding task, and it has been shown in earlier studies, e.g., by Kluge (2007) that performance of complex tasks is strongly affected by different training methods and their interaction with person-related variables. If we could demonstrate the interaction effects for vocational settings as well, there would be a strong need to carefully adapting training to individual prerequisites and/or preferences to achieve the best training outcome.

\section{Empirical evidence for interactions}

Summaries of theoretical and empirically studied models to generally understand the impact of individual differences, such as cognitive abilities, personality and cognitive style in the training context, are provided by Cannon-Bowers et al. (1995) and Colquitt et al. (2000). Although these models are widely agreed upon, the influence of individual differences in combination with specific training methods for adult and vocational training has not often been addressed. Results relevant for this study show the following:

\subsection{General mental abilities}

In general, based on Ree et al. (1995), Schmidt and Hunter (1998) and Salas and Cannon-Bowers (2001), cognitive ability influences the attainment of job knowledge and predicts training outcomes. Ability is assumed to directly affect how much a trainee learns and in what time (Gully et al. 2002).

The training outcomes, such as performance and acquired knowledge in weakly structured training situations, were found to be dependent on the abilities of the trainee. Snow and Lohman (1984) conclude that highability learners do especially well under instruction that is "significantly incomplete, because it demands and affords opportunities for the idiosyncratic exercise and elaboration of such organization" (p. 371).

In that respect, Gully et al. (2002) and Kluge (2007) found that high-ability trainees showed the highest task performance and had significantly higher levels of selfefficacy in a weakly structured situation with errorencouragement instructions. In contrast, lower-ability trainees showed better task performance and had significantly higher levels of self-efficacy when they received training in a strongly structured situation, i.e., erroravoidance instructions and direct instructions. Goska and Ackerman (1996) also concluded that learners with low scores in reasoning ability benefited more from a structured procedural training. These results mainly suggest that lower ability learners need more structure.

\subsection{Personality}

The work by Barrick and Mount (1991) or Salgado et al. (2003) showed that some of the Big Five Personality Dimensions, such as conscientiousness, extraversion and 
openness to new experiences, show consistent relations with training proficiency. Especially conscientiousness proved to be a good predictor of training proficiency in different occupational groups in general (Barrick and Mount 1991). Conscientiousness is often viewed as a trait-oriented motivation variable that tends to be correlated with behavior predictors of performance, such as reliability and effort (Herold et al. 2002). Conscientiousness relates to educational achievement because it assesses personal characteristics such as persistence, planfulness, carefulness, responsibility and being hard working (Barrick and Mount 1991). But conscientiousness has also been said to include cautiousness and criticality and the tendency to avoid mistakes (Gully et al. 2002). With respect to an interaction of conscientiousness with different training methods, two possible effects have to be considered. On the one hand, highly conscientious learners, due to their need to be cautious and avoid mistakes, may have difficulty in learning from errors because it might be inconsistent with their disposition to focus on avoiding errors. For example, with respect to interactions, trainees higher in conscientiousness were found to be negatively affected by errorencouragement in weakly structured situations leading to a lower self-efficacy after training (Gully et al. 2002). On the other hand, due to their disposition of being persistent, planning ahead and hard working, highly conscientious learners are better able to deal with lessstructured training methods even though they experience themselves as making errors during the learning process. For example, a study by Herold et al. (2002) showed that learners who were high in conscientiousness but experiencing early difficulty in learning a complex task required significantly fewer hours to attain the training criteria than those who experienced early difficulties and were low in conscientiousness.

It is difficult to predict which of these two possible effects of conscientiousness will prevail, but we consider the second assumption to be more important in our study. The reason is that error training in a complex setting, such as the one used in this study, can only provide successful learning opportunities for trainees if they systematically invest time and effort. They have to thoughtfully and persistently investigate what is affected by their actions, as well as carefully consider the feedback information and conduct further investigations if the error-related feedback is equivocal and cannot be easily understood and interpreted. Our arguments suggest that trainees with higher conscientiousness will be better able to deal with these learning conditions and that trainees with lower conscientiousness need more strongly structured training methods as they are less persistent.

\subsection{Cognitive style}

Cognitive styles are characterized by stable attitudes, preferences or habitual strategies as individual differences in the way people perceive, think, solve problems and learn (Kozhevnikov 2007). Cognitive styles represent heuristics that can be identified at each level of information processing, from perceptual to meta-cognitive (Kozhevnikov 2007), and are independent of intelligence and personality (Riding 1997). Sadler-Smith and Riding (1999) investigated relationships between cognitive style and instructional preferences. They assessed cognitive styles using the Cognitive Styles Analysis (CSA). The CSA assesses wholist-analytical (organizing information in components vs. global) and verbalizer-imager dimensions (verbal vs. pictorial representation of information). Results showed that wholists expressed a stronger preference for collaborative methods (e.g., role-plays, group discussions). Imagers tend to be more internal and passive, whereas verbalizers tend to be external and stimulated (Riding and Cheema 1991; Gully and Chen 2010). Cognitive flexibility is a cognitive style consisting of beliefs and preferences about learning as these relate to advanced knowledge acquisition in complex domains (Spiro et al. 1996). This construct is described as bipolar: individuals with a reductive cognitive style prefer simple and inflexible prescriptions from memory and show a low tolerance to ambiguity of situations and information. In contrast, an expansive and flexible cognitive style incorporates the assumption that the world is unorderly and heterogeneous which calls for a flexible and situation-adaptive assembly of knowledge (Spiro et al. 1996). Jacobson and Spiro (1995) report a significant interaction between cognitive flexibility and performance on a transfer test. Participants who scored in the cognitive/flexible range and used a complex non-linear hypertext for skill acquisition performed better in the transfer condition than those participants who scored in the simple/rigid/reductive range of the cognitive flexibility scale. In an earlier study by Burkolter et al. (2009), participants with a reductive cognitive style tended to perform better in controlling parameters in the simulation of a complex system, whereas participants with an expansive and flexible style tended to perform better in diagnosing and repairing deviations that occurred in the system.

These results suggest that the acquisition of knowledge and skills in weakly structured training contexts is positively affected by a flexible cognitive style and inhibited by a reductive cognitive style.

In summary, in this study, and according to the cited studies, we assume that general mental abilities, conscientiousness and cognitive style (flexible vs. reductive) 
interact with training methods on the performance of a process control task. Our assumptions are the following:

(a) General mental abilities (GMA). Trainees with low GMA will gain more knowledge and show better task performance in a strongly structured than in a weakly structured training condition.

(b) Conscientiousness. Trainees low in conscientiousness will gain more knowledge and show better task performance in a strongly structured than in a weakly structured training condition.

(c) Cognitive Style. Trainees scoring low on the expansive and flexible cognitive style will acquire more knowledge and show better performance when trained in a strongly structured than in a weakly structured training condition.

\section{Method}

To test our assumptions, we used a set of data which we extracted from a training experiment conducted in our research group in 2007 (Kluge et al. 2010). This training experiment was designed to address two groups of questions. The first one concerned questions regarding the support of skill retention over long periods of non-use (temporal transfer) and of skill application in situations not encountered in the training (adaptive transfer). The second one concerned the aspects of aptitude and attribute by treatment interaction. This paper focuses on the interactions data. The training methods we compared to test our assumptions were "Drill \& Practice" (D\&P), a strongly structured training method which has so far shown to be most beneficial for near and temporal transfer (Wickens and Hollands 2000; Kluge and Schüler 2007). For the weakly structured training situation, we used "error training" (ET), a very open training method with higher degrees of freedom such as discovery which proved to be most beneficial for far/adaptive transfer (Hesketh 1997). In the present study, we used the strategy of self-correction of guided errors (Lorenzet et al. 2005), in which trainees "are instructed or guided to errors in a manner that makes it clear that errors are an expected part of the learning experience" (Lorenzet et al. 2005, p. 303)

We will use the terminology near and far transfer as described in the introduction for the performance in trained and untrained tasks, respectively. The distinction of temporal and adaptive transfer in the other paper contains a temporal dimension (skill retention over time) we did not take into account when looking at the aptitude/ attribute by treatment interactions. For the same reason, we only used the data from the first post-test 9 weeks after the training, whereas the analyses comparing the training conditions take into account another post-test after 13 weeks.

\subsection{Participants}

A total of 38 apprentices participated in this quasi-experimental study (1 woman). They were all communication electronics apprentices of a large German telecommunication provider. This was to ensure that they had a basic understanding of technical systems. We assigned trainees to experimental conditions according to the location of the vocational training centers to which they belonged (Frankfurt and Leipzig), resulting in two groups of 18 (D\&P) and 20 (ET) participants, respectively. The participants' ages ranged from 17 to 25 years $(M=18.9)$.

All apprentices were in the second year of their vocational training. The two groups did not differ with respect to the individual differences variables (see Table 1). No pretest to control individual differences in prior knowledge was used, because the computer-based simulation employed contains relations between system variables that do not match real physical or chemical processes. There is no specific prior knowledge which would support learning the simulation task.

\subsection{The process control task}

The acquisition of knowledge and skills was trained and tested employing a simulated process control environment called Cabin Air Management System (CAMS). A number of previous studies have already used CAMS as an experimental task (e.g., Hockey et al. 2007; Sauer et al. 2008). CAMS models a process control task in the operational context of a spacecraft's automated life support system and consists of five main system variables that are maintained in a target zone by automatic controllers: oxygen $\left(\mathrm{O}_{2}\right)$, carbon dioxide $\left(\mathrm{CO}_{2}\right)$, cabin pressure, temperature and humidity. The participants have to monitor the system to ensure that it is stable, i.e., that all parameters remain within their target zone, and they need to intervene in case of a system fault. These two tasks, system stabilization and fault finding and repair, are defined as

Table 1 Descriptive statistics and $t$-tests of the individual differences variables for the two training groups

\begin{tabular}{|c|c|c|c|c|c|c|}
\hline & \multicolumn{2}{|c|}{$\begin{array}{l}\mathrm{D} \& \mathrm{P} \\
(n=18)\end{array}$} & \multicolumn{2}{|c|}{$\begin{array}{l}\mathrm{ET} \\
(n=20)\end{array}$} & \multirow[t]{2}{*}{$t(d f=36)$} & \multirow[t]{2}{*}{$p$} \\
\hline & $M$ & SD & $M$ & $\mathrm{SD}$ & & \\
\hline General mental abilities & 23.22 & 5.55 & 21.55 & 5.06 & -0.972 & $>.05$ \\
\hline Cognitive style & .31 & 1.04 & .30 & .94 & -0.041 & $>.05$ \\
\hline Conscientiousness & 6.90 & .85 & 6.96 & .61 & 0.242 & $>.05$ \\
\hline
\end{tabular}


primary tasks. There are also two secondary tasks. However, these are not analyzed in the present study, because they were not addressed by the training objectives.

\subsection{Individual differences}

\subsubsection{General mental abilities}

The Wonderlic Personnel Test (Wonderlic Inc. 2002) was employed to assess participants' cognitive abilities. The test is composed of 50 items and captures verbal, numerical, together with figural aspects of intelligence and learning aptitude. Twelve minutes were given for completion of the test.

\subsubsection{Conscientiousness}

Conscientiousness was measured using Saucier's (1994) Big Five Markers. Eight adjectives (such as organized, systematic or careless) had to be rated by participants on a 9-point scale ranging from 1 (extremely inaccurate) to 9 (extremely accurate). Internal consistency of the scale was satisfactory (Cronbach's Alpha $=.76$ ).

\subsubsection{Cognitive style}

The Cognitive Flexibility Inventory by Spiro et al. (1996) was used to capture cognitive flexibility. A 9-point scale ranging from -4 (one statement) to +4 (versus other statement) was employed. A sample item from the scale was: 'Learning works best under the guidance of experts (e.g., teachers) versus learning works best when it is selfdirected'. Cronbach's alpha was .70.

\subsection{Training methods}

Participants were trained on the complex task in one of two training conditions. The study contained an introductory phase which was identical for all participants and a training phase, during which the two training methods were varied. Participants were trained by two female trainers in groups of generally 10 persons. Participants worked individually on their computers during the training and testing sessions. The duration of the training session was approximately 5 hours (including two 15-minute and one 45-minute breaks).

In the introductory phase, all participants listened and watched a multimedia-based introduction to CAMS, its features and the primary and secondary tasks with headsets. After this 10-minute introduction, participants were provided 5 min to explore CAMS on their own for the first time. Following the introductory phase, the training groups received their training to practice dealing with the following five system faults: Nitrogen $\left(\mathrm{N}_{2}\right)$ valve permanently open, cooler set point failure, blocked $\mathrm{O}_{2}$ valve, $\mathrm{CO}_{2}$ scrubber ineffective and leak in $\mathrm{O}_{2}$ valve.

The two training groups worked with a manual in which all 16 possible fault states were described with their symptoms and the procedure how to stabilize the system before the repair process could be started (see Table 2). Furthermore, the training groups received additional graphical material for the five system faults dealt with in training (see Figs. 1, 2).

Participants in the D\&P group learned to diagnose and repair five system faults and stabilize the system by following detailed instructions. Instructions included descriptions on fault diagnosis/repair and system stabilization in a step-by-step manner (e.g., "Increase oxygen in the automatic controllers of the oxygen settings from 'default' to 'high'", see Fig. 1). These instructions were the same in the manual and in the graphical material. The D\&P group did five exercises on every system fault as the goal was to provide them with a lot of practice, corresponding to the rationale of D\&P ("practice makes perfect"). The five exercises per fault took $30 \mathrm{~min}$ to complete.

Table 2 Extract from CAMS-Manual for the fault state "leak in oxygen valve"

\begin{tabular}{ll}
\hline Leak in oxygen valve & \\
\hline Description of system fault & $\begin{array}{l}\text { Oxygen leaks from the valve (which is located at the oxygen tank). This results in a reduced oxygen } \\
\text { supply in the space craft }\end{array}$ \\
1. The oxygen graph shows a reduced amplitude and declines below norm range & 2. Oxygen flow rate does not correspond to the decline rates of the oxygen tank \\
Intervention: system control & $\begin{array}{l}\text { 1. Increase oxygen in the automatic controllers of the oxygen settings from "default" to "high" } \\
\text { and fault repair }\end{array}$ \\
$\begin{array}{l}\text { 2. When the system is stabilized, i.e., all parameters are in normal range, select "maintenance" } \\
\text { and conduct fault fixing }\end{array}$ \\
$\begin{array}{l}\text { 3. Monitor the parameters: pay attention during the one minute-fault fixing duration that all } \\
\text { parameters are in normal range }\end{array}$ \\
4. Set the flow settings on "default" again after fault fixing
\end{tabular}




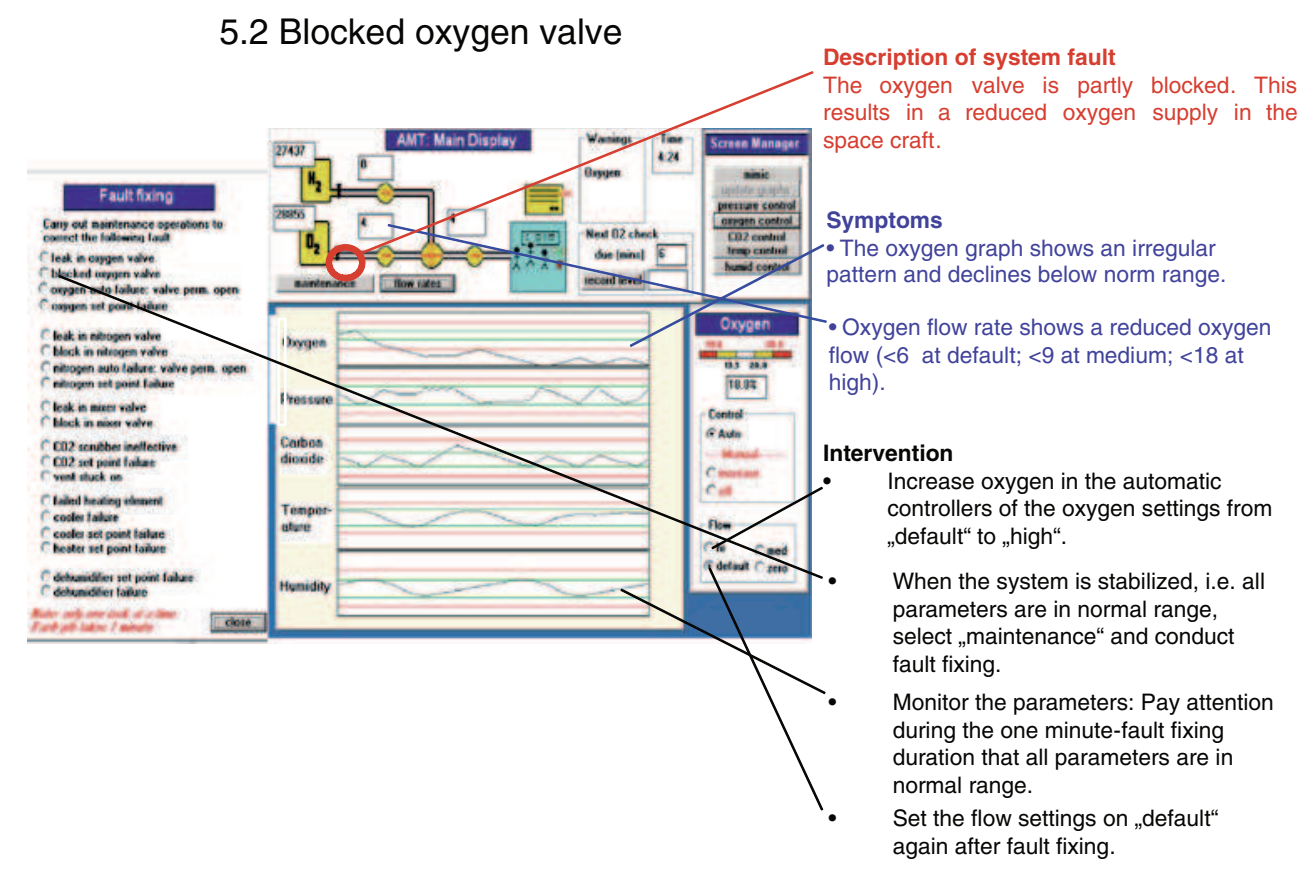

Fig. 1 Example of a worksheet for the D\&P group

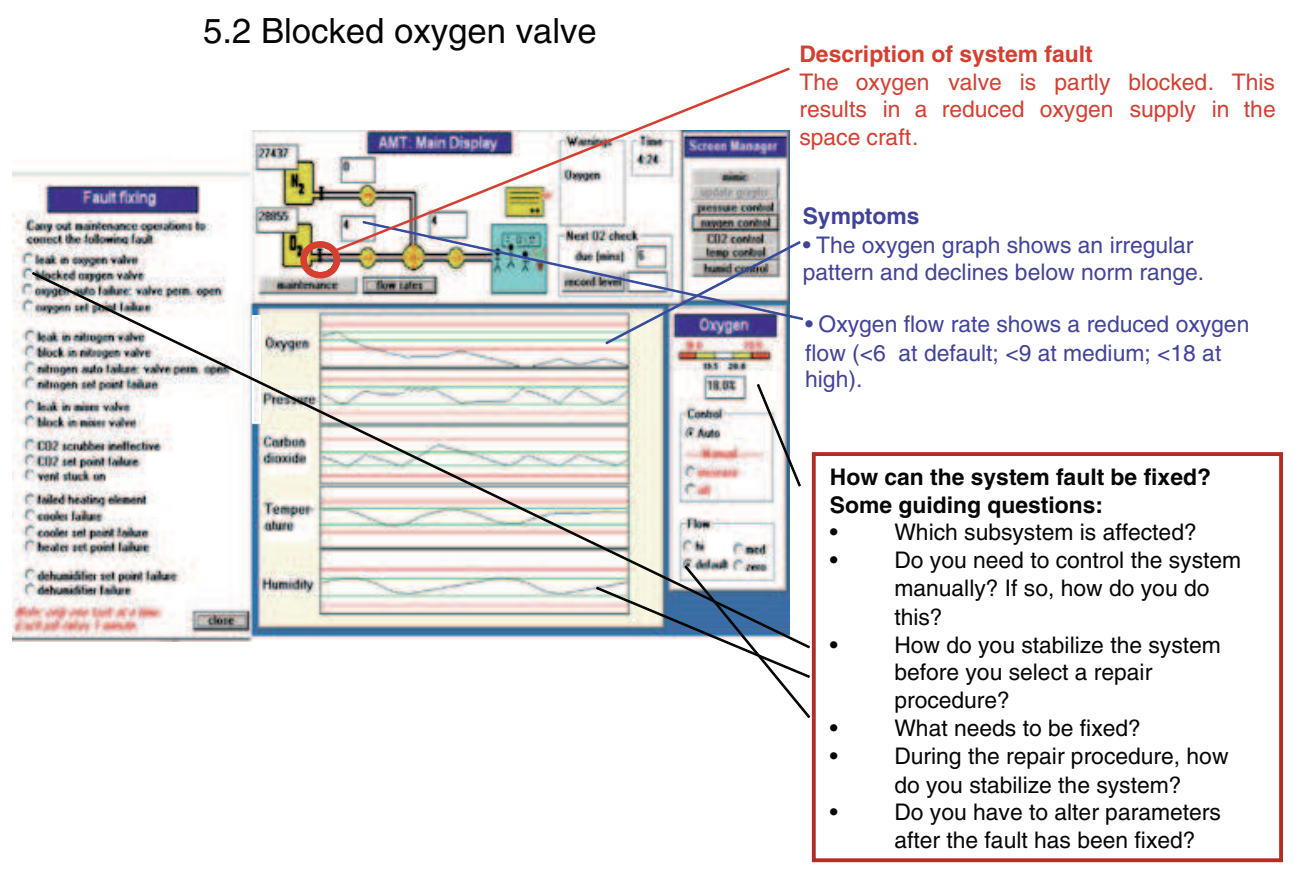

Fig. 2 Example of a worksheet for the ET group (guiding questions highlighted in the square)

The participants receiving ET were encouraged to make errors and improve their learning by drawing consequences out of these errors. Explanations of the trainers and written statements such as "Errors are a natural part of the learning process!", "The more errors you make, the more you learn!" pointed out the beneficial function of errors. The statements were presented on posters and cards as reminders. Furthermore, the graphical material for the ET group contained guiding questions on how to repair a system fault or to stabilize the system (see Fig. 2). Nevertheless, participants had access to the detailed step-by-step instructions as well, as they could also use the manual. 
Participants were encouraged to answer the questions on their own and test their answers during the following three exercises per fault with the goal to support their self-guided learning process. They also practiced the five faults mentioned above. The three exercises per fault took $30 \mathrm{~min}$ to complete, i.e., they took the same amount of time as the five exercises per fault of the D\&P group.

The guiding questions given to the ET group were derived from an analysis of the typical errors committed by participants when working with CAMS (Burkolter et al. 2007) using the cognitive reliability and error analysis method (CREAM, Hollnagel 1998) on the log-files of 39 chemical laboratory apprentices working on an untrained system fault (representing a far transfer condition) 1 week after a 5-hour CAMS training. Most errors were committed concerning decision, sequencing and timing. In situations with several action alternatives, wrong decisions were taken. Burkolter et al. (2007) state the decision whether to adopt manual control of a CAMS parameter or to adjust the automatic controllers as an example. Sequencing errors were coded when actions were omitted or when participants jumped forward or did wrong actions. Timing errors include actions that were started too late or not at all. According to the authors, no actions were conducted too early. Furthermore, think aloud protocols of 29 of the participants recorded while controlling CAMS were analyzed using the sub-goal templates method (SGT, Ormerod and Shepherd 2004) adapted to the CAMS environment. This analysis showed that good performers (top 25\%, $n=7$ ) "explained, formed rules and planned up to one and a half times as much as poor performers" (Burkolter et al. 2007, p. 481). From these results, the following questions used in the ET condition were devised to help participants avoid the common errors and facilitate fruitful cognitive actions such as planning. The questions needed to be answered by using the manual:

- Which subsystem is affected?

- Do you need to control the system manually? How do you stabilize the system before you select a repair procedure?

- What needs to be fixed?

- During the repair procedure, how do you stabilize the system?

- Do you have to alter parameters after the fault has been fixed?

\subsection{Testing procedure}

Nine weeks after the initial training, knowledge acquisition and performance were measured in the same groups as in the training session. The long retention interval between training and testing represents the transfer requirements of process control skills, because it is likely that acquired skills have to sustain longer periods of non-use (Kluge et al. 2009).

The test session consisted of two 35-minute testing periods and was identical for both training groups. To refresh skills and knowledge, participants were given the same multimedia-based introduction to CAMS as in the training session. During the testing session, participants were to apply the acquired skills on CAMS. The testing session included three fault states that were also part of the initial training (near transfer), and three fault states that were not addressed in the initial training (far transfer).

\subsection{Performance measures}

\subsubsection{Knowledge}

The questionnaire covering declarative and procedural knowledge consisted of 24 items. Part I for declarative knowledge included 12 multiple choice questions on the system (e.g., "What happens to pressure when the $\mathrm{CO}_{2}$ scrubber is on?") with three alternatives ("increase", "decrease", "minimal or no effect") followed by an open question to explain the given answer ("Please explain why"). Also, three open questions about the relationships between the system components and parameters in the CAMS environment had to be answered (e.g., "Please explain which components or processes have an impact on temperature in the cabin and describe the direction of the relationship"). Part II on procedural knowledge included 12 items concerning fault definitions, symptoms and repair instructions for near and far transfer. Test performance was measured by counting the percentage of correct answers in part I and II separately and by then averaging the percentage of correct answers. Cronbach's alpha was $=.73$.

\subsubsection{Performance}

Performance was measured by two main tasks. Percentages are reported to facilitate comparisons with other studies conducted with CAMS (e.g., Hockey et al. 2007; Sauer et al. 2008) which also used percentages.

(a) System stabilization. Learners had to maintain the five key parameters in a predefined zone and intervene in case a parameter departed from normal range. This can be achieved by means of adjustments of automatic controllers or by adapting manual control. We measured system control failures, i.e., the percentage of time a parameter was out of its target range.

(b) Fault diagnosis and repair. In case of a system fault, the learners needed to diagnose the fault and then repair the correct fault state as quickly as possible by 
means of the maintenance facility. We measured correct fault diagnoses, i.e., the percentage of correctly repaired faults of all occurring faults.

\subsection{Data analysis}

We conducted a series of multiple regressions with training and individual differences variables as predictors and the different performance measures as criteria. The individual differences variables were $\mathrm{z}$-standardized, and the training conditions dummy-coded. We coded the D\&P group as 1 and the ET group as -1 . For all regression analyses, we entered the training condition variable first, followed by the individual differences variable. In the third step, we entered the training condition $x$ individual differences variable. The main effects can be tested in the first two steps, whereas the interaction is evaluated in the third step. The significance is determined by the increment in $R^{2}$, i.e., variance explained (West et al. 1996).

Where we found a significant main effect of an individual differences variable, but no interaction with training condition, we used significant correlations to check the direction of the significant relationship from the regression. Positive correlations indicate that the main effect means that a high value in the individual differences variable matches a high value in the performance variable, whereas negative correlations indicate the opposite.

\section{Results}

Below, we will report significant effects concerning the interactions of the individual differences variables $G M A$, conscientiousness and cognitive style with training condition, as well as main effects of the individual differences variables.

\subsection{Descriptive statistics and correlations}

General descriptive statistics and correlations are presented in Table 3. Cognitive style was positively related to system stabilization during near and far transfer. Neither GMA nor conscientiousness was significantly related to acquired knowledge or performance. With respect to interdependencies between individual differences variables, there were no significant relationships between GMA, cognitive style or conscientiousness. However, weak and nonsignificant relations between conscientiousness and GMA as well as conscientiousness and cognitive style were found.

\subsection{Testing interaction effects}

\subsubsection{General mental abilities (GMA)}

We expected that trainees with low GMA would gain more knowledge and show better task performance in the strongly structured D\&P condition than in the weakly structured ET condition.

4.2.1.1 Acquired knowledge No significant interactions and no main effect of GMA on the knowledge criterion could be found.

4.2.1.2 Performance We obtained a significant interaction between GMA and training condition for fault diagnosis during near transfer, i.e., for practiced fault states (see Fig. 3; Table 4): Training condition, GMA and the interaction accounted for $40.2 \%$ of the variance in performance $\left(p<.05, f^{2}=.67\right)$. Surprisingly, training condition did not make a difference in the performance outcome for trainees low in GMA. On the contrary, the interaction showed that trainees with high GMA performed better in the D\&P condition than in the ET condition. No results

Table 3 Descriptive statistics and correlations between variables of interest

\begin{tabular}{|c|c|c|c|c|c|c|c|c|c|c|}
\hline & $M$ & SD & 1 & 2 & 3 & 4 & 5 & 6 & 7 & 8 \\
\hline 1. General mental abilities & 22.34 & 5.29 & 1.00 & & & & & & & \\
\hline 2. Cognitive style & .30 & .98 & -.02 & 1.00 & & & & & & \\
\hline 3. Conscientiousness & 6.93 & .72 & -.25 & .23 & 1.00 & & & & & \\
\hline 4. Acquired knowledge (\% correct answers) & 63.91 & 18.49 & .09 & -.08 & -.15 & 1.00 & & & & \\
\hline \multicolumn{11}{|l|}{ Near transfer } \\
\hline 5. Correct fault diagnoses (\%) & 44.74 & 36.58 & .27 & -.01 & -.04 & $.40^{*}$ & 1.00 & & & \\
\hline 6. System stabilization (\% of time out of range) & 2.94 & 3.03 & .00 & $.36^{*}$ & -.01 & -.21 & -.27 & 1.00 & & \\
\hline \multicolumn{11}{|l|}{ Far transfer } \\
\hline 7. Correct fault diagnoses (\%) & 33.33 & 25.70 & .26 & -.32 & -.10 & .06 & .29 & -.27 & 1.00 & \\
\hline 8. System stabilization (\% of time out of range) & 7.67 & 4.79 & .01 & $.34 *$ & .06 & -.17 & -.09 & $.54 * *$ & -.24 & 1.00 \\
\hline
\end{tabular}

$* p<.05 ; * * p<.01$ (two tailed) 


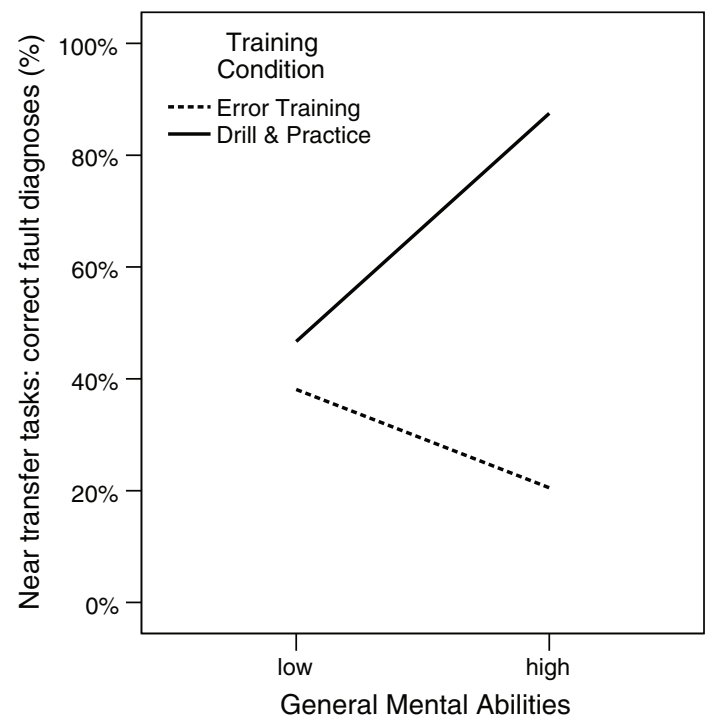

Fig. 3 Interaction of training condition and GMA on fault diagnosis during near transfer

Table 4 Regression of training condition and GMA on fault diagnosis during near transfer

$\begin{array}{llll}B & \text { SE } B & \beta & \text { Significance }\end{array}$

Step 1

Training condition

Step 2

Training condition

$\begin{array}{rrrl}19.07 & 5.12 & .53 & .00 * * \\ 17.96 & 5.12 & .50 & .00 * * \\ 6.33 & 4.65 & .19 & .18\end{array}$

General mental abilities

Step 3

Training condition

$\begin{array}{llll}17.97 & 4.86 & .50 & .00 * *\end{array}$

General mental abilities

$\begin{array}{llll}5.98 & 4.41 & .18 & .18\end{array}$

Training condition $\times$ general

$9.81 \quad 4.41 \quad .30 \quad .03 *$
mental abilities

$\overline{R^{2}=.279 \text { for Step } 1 ; \Delta R^{2}=.036 \text { for Step } 2 ; \Delta R^{2}=.087 \text { for Step } 3}$ $* p<.05 ; * * p<.01$ (two tailed)

proved significant concerning the fault diagnosis during far transfer, and no further results showed significant effects for system stabilization.

In summary, the main result for fault diagnosis during near transfer as a criterion shows the opposite of our assumptions. Trainees with high GMA showed a better performance in the D\&P condition than in the ET, while trainees low in GMA showed equal results in both training conditions.

\subsubsection{Conscientiousness}

Further, we expected that trainees low in conscientiousness would gain more knowledge and show better task
Table 5 Regression of training condition and conscientiousness on the amount of acquired knowledge

\begin{tabular}{lllll}
\hline$B$ & SE & $\beta$ & Significance \\
& $B$ & & \\
\hline
\end{tabular}

\begin{tabular}{lrrrl}
\hline Step 1 & & & & \\
Training condition & 4.00 & 2.97 & .22 & .19 \\
Step 2 & & & & \\
Training condition & 3.90 & 2.98 & .21 & .20 \\
Conscientiousness & -3.21 & 3.64 & -.14 & .38 \\
Step 3 & & & & \\
Training condition & 5.48 & 2.94 & .30 & .07 \\
Conscientiousness & -1.13 & 3.60 & -.05 & .76 \\
$\begin{array}{l}\text { Training condition } \times \\
\text { conscientiousness }\end{array}$ & -7.66 & 3.60 & -.35 & $.04^{*}$ \\
\hline$R^{2}=.048$ for Step $1 ; \Delta R^{2}=.021$ for Step $2 ; \Delta R^{2}=.109$ for Step 3 \\
$* p<.05$ (two tailed)
\end{tabular}

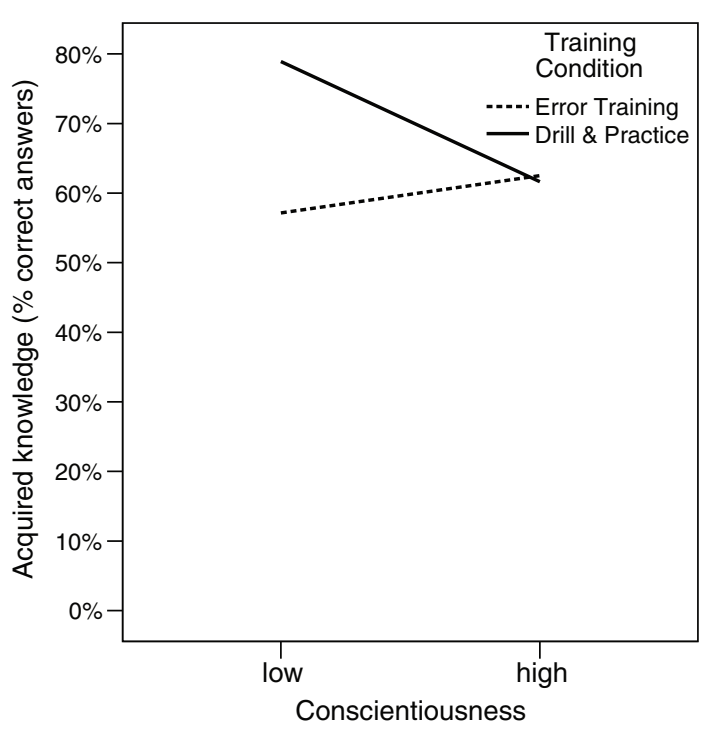

Fig. 4 Interaction of training condition and conscientiousness on acquired knowledge

performance in the strongly structured D\&P condition than in the weakly structured ET condition.

4.2.2.1 Acquired knowledge Our analyses showed a significant interaction between conscientiousness and training condition for the acquired knowledge criterion, but no main effects. Together, training condition, the amount of conscientiousness and the interaction accounted for $17.8 \%$ of the variance in acquired knowledge $\left(p<.05, f^{2}=.22\right.$; see Table 5). As can be seen in Fig. 4, less conscientious individuals tended to acquire more knowledge in the D\&P condition. This result is in line with our second hypothesis. 
4.2.2.2 Performance No significant results were found for performance by conscientiousness and the interaction with training condition.

\subsubsection{Cognitive style}

We finally assumed that trainees scoring low on the expansive and flexible cognitive style would acquire more knowledge and show better performance when trained with the strongly structured D\&P than with the weakly structured ET method.

4.2.3.1 Performance For the predictor cognitive style, we found a significant interaction effect for the system stabilization criterion during far transfer, accompanied by a significant main effect of cognitive style. Training condition, cognitive style and their interaction accounted for $33.3 \%$ of the variance in system stabilization during far transfer $\left(p<.01, f^{2}=.50\right.$; see Table 6$)$. In contrast to our assumption, Fig. 5 shows that, for participants with a lower score in cognitive flexibility, the training method did not make a difference. To the contrary, trainees scoring high in cognitive flexibility committed more errors in system control when trained in the ET group than when trained with D\&P. Furthermore, we found a main effect of

Table 6 Regression of training condition and cognitive style on system stabilization

$\begin{array}{llll}B & \text { SE } & \beta & \text { Significance } \\ B & & \end{array}$

System stabilization near transfer

Step 1

$\begin{array}{lrrrl}\text { Training condition } & -.89 & .48 & -.30 & .07 \\ \text { Step } 2 & & & & \\ \quad \text { Training condition } & -.89 & .45 & -.30 & .054 \\ \text { Cognitive style } & 1.06 & .44 & .36 & .02^{*} \\ \text { System stabilization far transfer } & & & & \\ \text { Step 1 } & & & & \\ \quad \text { Training condition } & -1.04 & .77 & -.22 & .19 \\ \text { Step 2 } & & & & \\ \quad \text { Training condition } & -1.05 & .73 & -.22 & .16 \\ \text { Cognitive style } & 1.56 & .72 & .34 & .04 * \\ \text { Step 3 } & & & & \\ \quad \text { Training condition } & -1.27 & .67 & -.27 & .07 \\ \text { Cognitive style } & 1.65 & .65 & .36 & .02^{*} \\ \quad \text { Training condition } \times & -1.93 & .65 & -.42 & .01^{* *} \\ \text { cognitive style } & & & & \end{array}$

System stabilization near transfer $R^{2}=.087$ for Step $1 ; \Delta R^{2}=.130$ for Step 2

System stabilization far transfer $R^{2}=.048$ for Step $1 ; \Delta R^{2}=.113$ for Step 2; $\Delta R^{2}=.172$ for Step 3

$* p<.05 ; * * p<.01$ (two tailed)

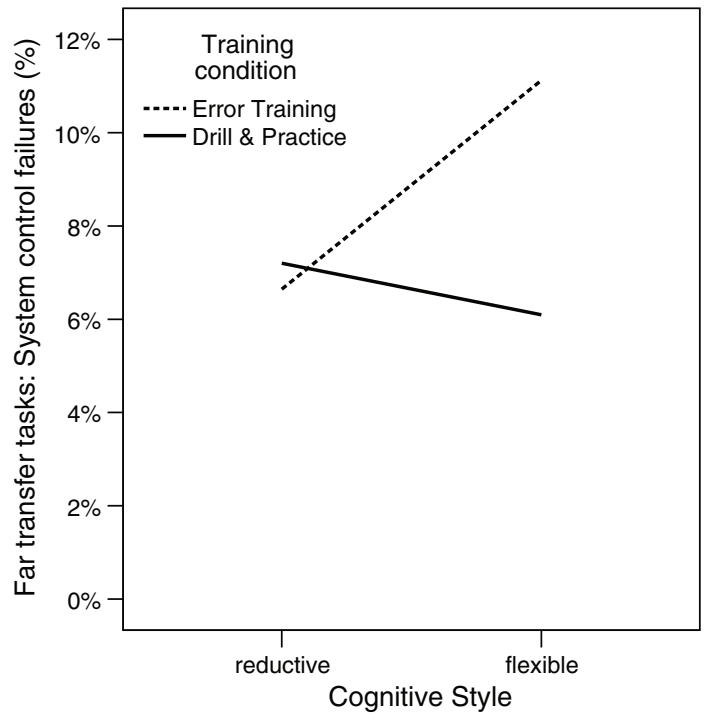

Fig. 5 Interaction of cognitive style and training condition on system stabilization during far transfer

cognitive style for the criterion of system stabilization during near transfer. Together with training condition, it accounted for $21.7 \%$ of the variance in system stabilization performance in near transfer situations $\left(p<.05, f^{2}=.28\right.$; see Table 6). The direction of this effect is reflected in a significant positive correlation of the two measures of $r=.36(p<.05$; see Table 3): Participants scoring high on the flexible cognitive style measure committed more errors in system stabilization. These results indicate that participants with a more flexible cognitive style tended to perform worse in system stabilization, especially in far transfer when trained in the ET condition.

The analysis of fault diagnosis during near and far transfer did not show an effect of cognitive style or an interaction.

In summary, surprising results were found in performance when regarding the knowledge measure and the two performance measures. Only the result for conscientiousness was as expected.

- The significant interaction between training condition and GMA showed that participants with low GMA reached the same performance in both training conditions. They were not supported by the structured training approach in D\&P. In contrast, trainees scoring high on GMA performed better in near transfer tasks when trained with D\&P.

- Conscientiousness in interaction with the training method affected knowledge acquisition. Less conscientious trainees acquired more knowledge in the D\&P condition. For highly conscientious individuals, training condition did not affect knowledge acquisition. 
- Cognitive style interacted with the training situation in far transfer system stabilization and directly affected near transfer system stabilization and fault diagnosis. A flexible cognitive style led to worse performance in system stabilization, especially in far transfer when participants were trained with ET. The more rigid the cognitive style of participants, the less their performance was affected by training condition.

\section{Discussion}

We started out by investigating the relationship between training methods and individual differences in order to contribute to a more personalized way of teaching, as for example suggested by the European Commission (2008a). Looking from a training method point of view, from the practice side, and from current trends in vocational training, we aimed at testing how certain learner groups react to different training methods and what impact on transfer performance these reactions produce.

Although we also found interactions in other directions than those hypothesized, they represent medium to large effect sizes between $f^{2}=.14$ and $f^{2}=.64$ (Cohen 1988 ${ }^{1}$ ) which give insights into how certain training methods affect successful learning and skill acquisition in interaction with individual differences.

Other than earlier studies which addressed less complex tasks (e.g., Keith and Frese 2008), one of our main conclusions is that for a complex task such as the CAMS process control task, a strongly structured training method is more likely to support learning. A second main conclusion is that individual differences do not generally penetrate but rather affect only particular learning outcomes. GMA in interaction with training influences diagnostic accuracy, and cognitive style and training make a difference with respect to system stabilization. In contrast, conscientiousness and training become important regarding knowledge acquisition. Especially, cognitive style seems to play an important role in predicting the performance in our process control task, as performance in near and far transfer tasks is influenced.

How do we interpret these various findings? We hypothesized that learners with low GMA will profit more in highly structured training situations with clear guidelines and defined steps, following results from Gully et al. (2002) and Kluge (2007). However, especially learners with high GMA profited from the highly structured D\&P condition and showed poorer results when dealing with practiced faults when trained in the weakly structured ET

\footnotetext{
${ }^{1}$ Effect sizes around $.02, .15$, and .35 be labeled small, medium, and large, respectively.
}

condition. On the other hand, learners with lower GMA benefited equally from both training methods. How can we explain this?

With regard to the lower GMA learners, we assume that individuals in both training groups followed the instructions accurately and thoroughly, because their educational socialization taught them that accurately following the instructions would be most profitable in their learning process. They might have been less courageous to actively explore beyond the limits of instructions given. They might have followed the guiding questions more closely (which means that they actually looked for the solutions in the manual) than the higher GMA group in the ET condition and used the guiding questions to systematically explore the simulation task which resulted in better performance for the D\&P group. From an experimental validity point of view (Cook et al. 1990), we suspect difficulties with the reliability of the ET treatment implementation. Due to the fact that ET places most of the responsibility for the learning activity on the learners themselves, from an experimenter's point of view, it is quite difficult to ensure that learners follow the instruction to make the most of errors, for example, and to use the guiding questions to work through the CAMS task. Therefore, in contrast to the D\&P condition with less degree of freedom to self-control learning activities, it is much more difficult to ensure that learners apply the ET instructions to learn in a self-directed manner. In further research, observational data might be gathered to analyze the learning strategy taken by the trainees, e.g., to what extent trainees used the manual to find answers to the guiding questions.

With respect to knowledge acquisition, we found that low conscientiousness learners are best supported by D\&P, whereas the training method is insignificant for highly conscientious learners. This finding is in line with our assumptions. Low conscientiousness learners are characterized as less persistent, diligent and planning ahead (Barrick and Mount 1991) and might lose motivation in weakly structured situations. Because of the fact that knowledge about the CAMS parameters and their relations was not explicitly taught, knowledge acquisition was primarily dependent on the deduction of the relations from the information given in the manual (which had to be used in the D\&P condition) or on deriving them from learning from errors and the guiding questions (as provided in the ET condition). In ET, learners had to put much more effort in knowledge acquisition than in the D\&P conditions, and this might be the reason why participants low in conscientiousness were better able to acquire knowledge in the more structured D\&P training. Remarkable is the fact that trainees high in conscientiousness profited less from the structured D\&P condition when acquiring knowledge than 
the trainees low in conscientiousness. According to Gully and Chen (2010), highly conscientious individuals set more challenging goals and are more committed to them. As the main tasks operating CAMS were system stabilization and fault finding and repair, it is possible that highly conscientious participants were more focused on these tasks and thus acquired less knowledge. Gully and Chen (2010) state that the evidence for conscientiousness and its impact on learning seems to be mixed because conscientiousness might enhance motivation and persistence but reduces attentional focus and leads to self-deception regarding learning progress (Martocchio and Judge 1997). Furthermore, they cite Herold et al. (2002), who propose that subfactors of conscientiousness, such as achievement striving or perseverance should be investigated separately to isolate and better understand the influence of conscientiousness on training outcomes. These aspects will be considered in further investigations.

Finally, performance in general, but especially in far transfer, was affected by cognitive style. High cognitive flexibility led to poorer results in system stabilization. All in all, flexible style learners seem to be less able to operate the CAMS simulation, and ET training further impedes their performance.

This is surprising because according to the concept of cognitive flexibility as proposed by Spiro et al. (1996) especially cognitively flexible learners are supposed to perform better in far transfer situations in which acquired skills and knowledge need to be flexibly applied to new contexts. Cognitively flexible trainees are supposed to show preferences for complexity, ambiguity, heterogeneity and disorderliness and are even said to be bored by simplicity (Spiro et al. 1996). But in the CAMS context, it might be possible that they open up the problem space too widely, although fault identification and repair follows clear and fixed procedures. They might have used their cognitive resources to further explore the system and fault states instead of controlling it. Reductive style learners are more prone to stick to the manual and follow the given instructions, whereas learners with a flexible style might be induced to improvise and find solutions on their own. We assume that ET further facilitates this behavior. In far transfer, this "improvisation" might lead to a less successful fault repair strategy while losing sight of the system stabilization task.

Taken together, finally, possible interdependencies of the three person-related variables should be discussed. In their recent overview, Gully and Chen (2010) address the issue that individual differences might interact with each other. Personality traits might affect training through attentional focus, motivation and emotion regulation. GMA will also affect learning performance directly and indirectly through motivational variables such as self- efficacy and goals (Chen et al. 2000). In this study, direct interdependencies between GMA, conscientiousness and cognitive complexity do not seem reasonable from a theoretical point of view and relationships found between the three person-related variables were weak and nonsignificant. A learner might be highly conscientious but with lower GMA. In our study, apprentices benefited most from D\&P if they were highly conscientious, scored higher in GMA and lower in cognitive flexibility, leading them to gain more knowledge and to perform better. Because we did not measure motivation or effort during the learning process, it is difficult to argue how the measured variables differentially affected motivation or metacognitive strategies, for example.

There are limitations of this quasi-experimental study. In our attempt to maximize internal and external validity, we conducted the experiment in a vocational setting but used an artificial simulation task unknown to the participants to control for prior domain specific knowledge. And although we assumed that there is no specific prior knowledge that would support learning of CAMS and subsequent performance, experience with computer and simulation games could have an influence on performance. But empirical research points to no clear direction, e.g., earlier studies such as the study by Süss (1996) showed the impact of computer experience on the simulation performance, whereas more recent studies by Kluge $(2007$; 2008) did not. To further explore this assumption, future studies with CAMS should employ a pretest of previous computer game experience. With respect to external validity and generalization, it has to be considered that our sample included vocational trainees, learning how to operate a prior unknown simulation task and that performance measures were taken 9 weeks after the training without having opportunities for learning-on-the-job. This means that we implicitly measured the acquisition of pure context free learning material and the forgetting curve of this material.

In this respect, one additional shortcoming to which we have to concede is that we examined a specific group of participants for this investigation. As we required our participants to be apprentices who would be available as a group after a longer retention interval, we asked for the support of an organization which is sufficiently large to provide a number of apprentices for several training groups and retention intervals. The training groups were "real" groups of apprentices, rather than adhoc groups normally used in experimental settings. Group size was thus limited to the size of the existing groups, which led to the rather small number of participants. Future studies should try to reach a larger $N$.

Furthermore, in these groups, we observed the group dynamics usual for such a class, such as group members 
teasing, annoying or making fun of each other. Finally, participants were not paid or given any other credits for participating. They were given 200 EUR after the final testing session for the whole group. Thus, there was no direct incentive to invest effort and engage in the learning task. Additionally, the task, the CAMS simulation, is an artificial learning environment and had no direct relevance for their further vocational training. Finally, apprentices in all groups did not participate voluntarily. Instead, their vocational trainers and supervisors volunteered and agreed to participate in the study because they hoped to gain more insight into the methods and the effects involved. Although this applies to both training groups, we assume that due to the special requirements regarding self-regulation, the ET group probably had more motivational problems in terms of keeping up selfmonitoring, self-evaluation and self-reaction in the reallocation of attention. This is addressed, for instance, by Gully and Chen (2010).

\subsection{Implications for research}

From a theoretical and methodological point of view, there are several differences between our experiment and previous studies, on which we built our theoretical assumption. We have concentrated our interpretation on one exemplary study, because the Gully et al. (2002) study was one of few who studied the interaction effects of training and similar individual differences in detail. Comparing our study to that of Gully et al. (2002), which serves as an anchor to display differences to our experimental design, there are several differences between these two studies.

First, there is the task to be learned. Although both tasks share aspects of complexity, the CAMS task and the task trained by Gully et al. (2002) differ with regard to the amount of transparency, and to the amount of their dynamic properties (see Kluge 2007). CAMS is much more dynamic and opaque than the radar-tracking and decision-making task used by Gully et al. (2002). Also, considering the types of tasks that were integrated in the meta-analysis by Keith and Frese (2008) investigating the effects of ET, such as proceduralized trainings for word processor, web browser or email, suggests that the ET effects might be limited to less dynamic and more transparent tasks. Further, as shown in a study by Kluge (2007), the more dynamic and opaque the task to be learned was, the less effective weakly structured training methods became, because learners experienced greater difficulties to deduce and understand the relationships between variables. Although our explanation is limited because we did not compare the interaction effects in simpler versus complex tasks, we would like to focus here on the complex task characteristics. The challenge of the CAMS simulation is that the feedback cues after making an error are not always salient. There is no acoustic or visual sign that tells the learner that he or she has made a mistake. The warning sign that appears is related to the parameter that is affected by an erroneous action of the operator. The simulation is constantly running and does not stop when waiting for the right "key to be pressed", as in earlier studies using simpler software programs that needed to be learned. Errors made by the learners can accumulate and the feedback provided by the system becomes increasingly difficult to interpret.

Second, the training period was taken into consideration. While our training took $5 \mathrm{~h}$ in total to train five faults, the training duration in the Gully study was three sessions of approximately $20 \mathrm{~min}$ each (ca. $60 \mathrm{~min}$ in all). It might be possible that individual characteristics affect learning in different ways depending on training time (i.e., for shorter and longer training durations different individual characteristics might gain importance), thus explaining the different results between the studies.

Third, while Gully et al. (2002) measured training performance (the final 7-min trial) directly after the training, we measured transfer performance 9 weeks later which means that we compared the performance after a long retention interval to the performance directly after the initial learning phase. Measuring performance after a retention interval ensures that a persisting training effect with relatively permanent changes in performance is measured and that a difference between groups does not vanish once the training manipulation is removed (Keith and Frese 2008).

Additionally, from a theoretical and methodological point of view, Gully et al. (2002) pointed out that only the individuals with the highest levels of ability benefited more from error-encouragement (p. 148), whereas for all others, training made no difference, or they even benefited more from error-avoidance training. While Gully et al. (2002) used the Scholastic Assessment Test (SAT)-Scores of participants (students), we used the Wonderlic Personnel Test. The SAT is specific to the North American school system, which hinders comparison of studies on an international level. Furthermore, the SAT-Scores might measure a different GMA-construct than the Wonderlic Personnel Test. Hence, future studies must carefully consider how GMA is measured and what construct lies behind it if their results are to be internationally compared with other studies.

In summary, further research should address the issues of interactions between individual differences and training methods in the context of task complexity and the learning conditions under which these occur. 


\subsection{Implications for practitioners}

According to the EU, preparing young people for the twenty-first century means to appreciate that every learner's needs differ and every classroom is a place of diversity with regard to gender, ability, or learning styles. To advance the competences of learners, it is necessary to teach in more personalized ways (European Commission 2008a, p. 6). In that respect, more flexible education and training pathways will facilitate knowledge and skill acquisition of the individual learner. But what does this mean in practice?

According to Jonassen and Grabowski (1993), when matching instruction to learner traits, several options seem reasonable: (a) preferential match: capitalizing on learner strengths or preferences, e.g., use illustrations for visual learners, (b) remediation match: eliminating deficiencies in learner traits by instructing skills how to learn which the learner has not yet acquired, (c) compensatory match: supplanting skills or learner traits by using an instructional design that compensates for learner deficiencies, (d) challenging learner skills by not accommodating their preferences and weaknesses in order to support an adaptation to different forms of instruction. The results for D\&P which least discriminated any learner group might indicate that the D\&P condition can serve as a compensatory or remediation match for participants with low conscientiousness or a flexible cognitive style. There are further indications that all learner groups can be supported by D\&P by compensating for their traits, e.g., seeing the world as disorderly for cognitive flexibility, or by eliminating deficiencies, e.g., lacking ability to plan ahead for individuals with low conscientiousness, by providing a good structure and focus. This seems to be especially important in such complex tasks as CAMS represents, and in which an adequate task and attention management is an important prerequisite for successful learning.

Our study might provide a starting point for further research on training methods that remediate and compensate learners' deficiencies and capitalize on learner strengths especially in complex learning environments.

Acknowledgments This project has been funded by the Swiss National Science Foundation (No. P001-106354).

\section{References}

Anderson JR, Fincham JM, Douglass S (1997) The role of examples and rules in the acquisition of a cognitive skill. J Exp Psychol Learn Mem Cognit 23:932-945

Barrick MR, Mount MK (1991) The Big Five Personality dimensions and job performance: a meta-analysis. Person Psychol 44:1-26

Bosch G, Charest J (2008) Vocational training and the labour market in liberal and coordinated economies. Ind Relat J 39:428-447
Burkolter D, Kluge A, Schüler K, Sauer J, Ritzmann S (2007) Cognitive requirements analysis to derive training models for controlling complex systems. In: De Waard D, Hockey GRJ, Nickel P, Brookhuis KA (eds) Human factors issues in complex system performance. Shaker Publishing, Maastricht, pp $475-484$

Burkolter D, Kluge A, Sauer J, Ritzmann S (2009) The predictive qualities of operator characteristics for process control performance: the influence of personality and cognitive variables. Ergonomics 52:302-311

Cannon-Bowers JA, Salas E, Tannenbaum SI, Mathieu JE (1995) Toward theoretically based principles of training effectiveness: a model and initial empirical investigation. Mil Psychol 7:141-164

Cassidy S (2004) Learning styles: an overview of theories, models and measures. Educ Psychol 24:419-444

Chen G, Gully SM, Whiteman JA, Kilcullen BN (2000) Examination of relationships among trait-like individual differences, state-like individual differences, and learning performance. J Appl Psychol 85:835-847

Cohen J (1988) Statistical power analysis for the behavioral sciences, 2nd edn. Erlbaum, Hillsdale

Colquitt JA, LePine JA, Noe RA (2000) Toward an integrative theory of training motivation: a meta-analytic path analysis of 20 years of research. J Appl Psychol 85:678-707

Cook T, Campbell D, Peracchio L (1990) Quasi experimentation. In: Dunnette M, Hough LM Handbook of industrial and organizational psychology, vol 1, 2nd edn. Consulting Psychologists Press, Palo Alto, pp 491-576

de Jong T (2006) Scaffolds for scientific discovery learning. In: Elen J, Clark RE (eds) Handling complexity in learning environments: theory and research. Elsevier, Amsterdam, pp 107-128

de Jong JAS, Wierstra RFA, Hermanussen J (2006) An exploration of the relationship between academic and experiential learning approaches in vocational education. $\mathrm{Br} \mathrm{J}$ Educ Psychol 76:155-169

Dormann T, Frese M (1994) Error training: replication and the function of exploratory behavior. Int $\mathrm{J}$ Hum Comput Interact 6:365-372

Ericsson KA, Krampe RT, Tesch-Römer C (1993) The role of deliberate practice in the acquisition of expert performance. Psychol Rev 100:363-406

European Commission (2008a) Improving competences for the 21st century. An Agenda for European Cooperation on Schools. COM(2008) 425. http://eur-lex.europa.eu/LexUriServ/ LexUriServ.do?uri=COM:2008:0425:FIN:EN:PDF. Accessed 6 December 2008

European Commission (2008b) Leaflet: progress towards the Lisbon objectives 2010 in education and training. http://ec.europa.eu/dgs/ education_culture/publ/pdf/educ2010/indicatorsleaflet_en.pdf. Accessed 6 December 2008

Foss MA, Fabiani M, Mané AM, Donchin E (1989) Unsupervised practice: the performance of the control group. Acta Psychol $71: 23-51$

Frese M, Zapf D (1994) Action as the core of work psychology: a German approach. In: Triandis HC et al (eds) Handbook of industrial and organizational psychology, vol 4. Consulting Psychology Press, Palo Alto, pp 271-340

Frese M, Brodbeck FC, Heinbokel T, Mooser C, Schleiffenbaum E, Thiemann P (1991) Errors in training computer skills: on the positive function of errors. Hum Comput Interact 6:77-93

German Federal Institute for Vocational Education and Training (2008) Hermann-Schmidt-Preis 2008: Auszeichnung für innovative Berufsbildung (Hermann-Schmidt-Award 2008: Award for innovative vocational education and training). http://www. bibb.de/dokumente/pdf/hermann_schmidt_preis_2008_bwp_ spezial_6_2008.pdf. Accessed 6 December 2008 
Ginzburg S, Dar-El EM (2000) Skill retention and relearning-a proposed cyclical model. J Workplace Learn 12:327-332

Goska RE, Ackerman PL (1996) An aptitude-treatment interaction approach to transfer within training. J Educ Psychol 88:249-259

Gully S, Chen G (2010) Individual differences, attribute-treatment interactions, and training outcomes. In: Kozlowski SWJ, Salas E (eds) Learning, training, and development in organizations. Routledge, New York, pp 3-64

Gully SM, Payne SC, Kiechel Koles KL, Whiteman J-AK (2002) The impact of error training and individual differences on training outcomes: an attribute-treatment interaction perspective. J Appl Psychol 87(1):143-155

Hacker W, Skell W (1993) Lernen in der Arbeit [Learning-on-theJob]. BIBB, Berlin

Hagman JD, Rose AM (1983) Retention of military tasks: a review. Hum Factors 25:199-213

Hanhart S, Bossio S (1998) Costs and benefits of dual apprenticeship: lessons from the Swiss system. Int Lab Rev 137:483-500

Heimbeck D, Frese M, Sonnentag S, Keith N (2003) Integrating errors into the training process: the function of error management instructions and the role of goal orientation. Person Psychol 56:333-361

Herold DM, Davis W, Fedor DB, Parson CK (2002) Dispositional influences on transfer of learning in multistage training programs. Person Psychol 55:851-869

Hesketh B (1997) Dilemmas in training for transfer and retention. Appl Psychol Int Rev 46(4):317-339

Hockey GRJ, Sauer J, Wastell DG (2007) Adaptability of training in simulated process control: knowledge- versus rule-based guidance under task changes and environmental stress. Hum Factors 49:158-174

Hollnagel E (1998) Cognitive reliability and error analysis method. Elsevier Science Ltd., Oxford

Ivancic K, Hesketh B (2000) Learning from errors in a driving simulation: effects on driving skill and self-confidence. Ergonomics 43:1966-1984

Jacobson MJ, Spiro RJ (1995) Hypertext learning environments, cognitive flexibility, and the transfer of complex knowledge: an empirical investigation. J Educ Comput Res 12(4):301-333

Jonassen DH, Grabowski BL (1993) Handbook of individual differences, learning and instruction. L Erlbaum Associates, Hillsdale

Keith N, Frese M (2008) Effectiveness of error management training: a meta-analysis. J Appl Psychol 93(1):59-69

Kirschner PA, Sweller J, Clark RE (2006) Why minimal guidance during instruction does not work: an analysis of the failure of constructivist, discovery, problem-based, experiential, and inquiry-based teaching. Educ Psychol 41:75-86

Kluge A (2007) Experiential learning methods, simulation complexity and their effects on different target groups. J Educ Comput Res 36(3):323-349

Kluge A (2008) Performance assessments with microworlds and their difficulty. Appl Psychol Meas 32:156-180

Kluge A, Schüler K (2007) Experience management by means of simulator trainings in high reliability organizations-re-enacting critical incidents and learning from experience-examples from nuclear power plants and oil refineries. In: Gronau N (ed) 4th Conference on professional knowledge management-experiences and vision. Gito, Berlin, pp 77-84

Kluge A, Sauer J, Schüler K, Burkolter D (2009) Designing training for process control simulators: a review of empirical findings and current practices. Theor Issues Ergon Sci, iFirst-article. Available at http://dx.doi.org/10.1080/14639220902982192

Kluge A, Sauer J, Burkolter D, Ritzmann S (2010) Designing training for adaptive and temporal transfer: a comparative evaluation of three training methods for process control tasks. J Educ Comput Res (in press)
Kluger AN, DeNisi A (1996) Effects of feedback intervention on performance: a historical review, a meta-analysis, and a preliminary feedback intervention theory. Psychol Bull 119:254-284

Kontogiannis T, Shepherd A (1999) Training conditions and strategic aspects of skill transfer in a simulated process control task. Hum Comput Interact 14:355-393

Kozhevnikov M (2007) Cognitive styles in the context of modern psychology: toward an integrated framework of cognitive style. Psychol Bull 133:464-481

Latham GP, Locke EA (1991) Self-regulation through goal setting. Organ Behav Hum Decis Process 50:212-247

Leberman S, McDonald L, Doyle S (2006) The transfer of learning. Participant's perspectives of adult education and training. Gower, Aldershot

Lorenzet SJ, Salas E, Tannenbaum SI (2005) Benefiting from mistakes: the impact of guided errors on learning, performance, and self-efficacy. Hum Resource Dev Q 16:301-322

Martocchio JJ, Judge TA (1997) Relationship between conscientiousness and learning in employee training: mediating influences of self-deception and self-efficacy. J Appl Psychol 82:764-773

Mattoon JS (1994) Designing instructional simulations: effects of instructional control and type of training task on displayinterpretation skills. Int J Aviat Psychol 4:189-209

Mayer RE (2004) Should there be a three-strikes rule against pure discovery learning? The case of guided methods of instruction. Am Psychol 59:14-19

Merrill MD (2001) First principles of instruction. J Struct Learn Intell Syst 14:459-466

Morris NM, Rouse WB (1985) Review and evaluation of empirical research in troubleshooting. Hum Factors 27:503-530

Ormerod TC, Shepherd A (2004) Using task analysis for information requirements specification: the sub-goal template (SGT) method. In: Diaper D, Stanton NA (eds) The handbook of task analysis for human-computer interaction. Lawrence Erlbaum Associates, Mahwah, pp 347-365

Patrick J, Grainger L, Gregov A, Halliday P, Handley J, James N, O'Reilly S (1999) Training to break the barriers of habit in reasoning about unusual faults. J Exp Psychol Appl 5:314-335

Postle D (1993) Putting the heart back to learning. In: Boud D et al (eds) Using experience for learning. Marston Lindsay Ross, Oxfordshire, pp 33-46

Ree MJ, Carretta TR, Teachout MS (1995) Role of ability and prior job knowledge in complex training performance. J Appl Psychol 80:721-730

Riding RJ (1997) On the nature of cognitive style. Educ Psychol 17:29-49

Riding RJ, Cheema I (1991) Cognitive styles: an overview and integration. J Educ Psychol 11:193-215

Sadler-Smith E, Riding R (1999) Cognitive style and instructional preferences. Instruc Sci 27:355-371

Salas E, Cannon-Bowers JA (2001) The science of training: a decade of progress. Ann Rev Psychol 52:471-499

Salgado JF, Moscoso S, Lado M (2003) Evidence of cross-cultural invariance of the big five personality dimensions in work settings. J Pers 17:S67-S76

Saucier G (1994) Mini-markers: a brief version of Goldberg's unipolar big-five markers. J Pers Assess 63:506-516

Sauer J, Burkolter D, Kluge A, Ritzmann S, Schüler K (2008) The effects of heuristic rule training on operator performance in a simulated process control environment. Ergonomics 51:953-967

Schendel JD, Hagman JD (1982) On sustaining procedural skills over a prolonged retention interval. J Appl Psychol 67:605-610

Schmidt FL, Hunter JE (1998) The validity and utility of selection methods in personnel psychology: practical and theoretical 
implications of 85 years of research findings. Psychol Bull 124:262-274

Snow RE, Lohman DF (1984) Toward a theory of cognitive aptitude for learning from instruction. J Educ Psychol $76: 347-376$

Sonntag K (1989) Trainingsforschung in der Arbeitspsychologie. Berufsbezogene Lernprozesse bei veränderten Tätigkeitsinhalten. [Training Research in Industrial Psychology. Vocational Education and Training for Changing Task requirements]. Huber, Bern

Spiro RJ, Feltovich PJ, Coulson RL (1996) Two epistemic worldviews: prefigurative schemas and learning in complex domains. Appl Cognit Psychol 10:S51-S61

Süss HM (1996) Intelligenz, Wissen und Problemlösen [Intelligence, knowledge, and problem-solving]. Hogrefe, Göttingen

Sweller J (1988) Cognitive load during problem solving: effects on learning. Cognit Sci 12:257-285

Sweller J (2006) How the human cognitive system deals with complexity. In: Elen J, Clark RE (eds) Handling complexity in learning environments: theory and research. Elsevier, Amsterdam, pp 13-27
Van Gog T, Ericsson KA, Rikers RMJP, Paas F (2005) Instructional design for advanced learners: establishing connections between the theoretical frameworks of cognitive load and deliberate practice. Educ Tech Res Dev 53:73-81

Van Gog T, Paas F, van Merrienboer JJG (2008) Effects of studying sequences of process-oriented and product-oriented worked examples on trouble shooting transfer efficiency. Learn Instruct $18: 211-222$

Van Merrienboer JJG, Kirschner PA, Kester L (2003) Taking the load off a Learner's mind: instructional design for complex learning. Educ Psychol 38:5-13

Watkins KE, Marsick VJ (1992) Building the learning organization: a new role for human resource developers. Stud Cont Educ 14:115-129

West SG, Aiken LS, Krull JL (1996) Experimental personality designs: analyzing categorical by continuous variable interactions. J Pers 64:1-48

Wickens CD, Hollands JG (2000) Engineering psychology and human performance, 3rd edn. Prentice Hall, Upper Saddle River

Wonderlic (2002) Wonderlic Personnel Test. Wonderlic Inc., Libertyville 